\title{
How are mental health problems perceived by a community in Agaro town?
}

\author{
Amare Deribew, Yonas Shiferaw Tamirat
}

\begin{abstract}
Background: In Ethiopia where poverty, war, famine, displacement and homelessness are common, mental health is also becoming a major public health problem. However, little is known about the perception of the public regarding mental health problems.

Objective: To describe the awareness and attitude of the public towards mental health problems.

Methods: The study used a community-based cross sectional survey conducted in Agaro town in December 2003. Three kebeles were randomly selected and the sample size for each kebele was determined based on probabilities proportional to area size. Data were collected by trained nurses supervised by investigators using a structured questionnaire and analyzed using chi-square and f-tests and the SPSS-11 version window program.

Results: A total of 728 people were interviewed with a response rate of $99.5 \%$. Most of the respondents were females (60\%), Oromo (38.2\%), Orthodox Christians (50.4\%), married (71.7\%) and housewives (37.7\%). Talking to oneself, sleep disturbance, strange behavior and aggression were the most commonly perceived symptoms of mental health problems. Poverty, "God's will", evil spirit and stress were traditionally implicated as causes of mental health problems. A person with an experiencing schizophrenia was perceived as suffering from mental health problems by $74 \%$ of the respondents. Only $15 \%$ of the study participant recognized major depression as a mental health problem. Educated people preferred modern medicine for the treatment of epilepsy, schizophrenia, major depressive disorder (MDD) and generalized anxiety disorder more often than less educated ones. Less educated people had a negative attitude to marital prospects and work opportunity of schizophrenic patients $(\mathrm{p}=0.0001)$. They also had more negative attitude towards educational opportunity a people for with epilepsy $(p=0.006)$. Illiterate respondents had negative attitude more than the literate respondents towards living with persons with epilepsy and schizophrenia in the same house $(\mathrm{p}=0.001)$.

Conclusion: Information education and traditionally communication (IEC) approaches should be used to teach about the symptoms, causes and treatment of mental health problems to change the irrational beliefs and negative attitude of the people towards mental health problems. [Ethiop.J.Health Dev. 2005;19(2):153-159]
\end{abstract}

\section{Introduction}

For all individuals, mental, physical and social health are vital elements of life that are closely interwoven and deeply interdependent. As an understanding of this relationship increases, it becomes even more apparent that mental health is crucial to the overall well being of individuals, societies, and countries (1).

Today, mental health problem is recognized as a public health problem in developed as well as developing countries. The notion that mental health problems are less common in low-income countries than in developed countries has long been disputed $(2,3)$.

At least 40 million people in the world suffer from severe forms of mental disorders such as schizophrenia and dementia. No fewer than 20 million people around the globe suffer from epilepsy which is also a mental disorder; and a further 200 million are incapacitated by less severe mental and neurological disorders such as neuroses and peripheral neuropathy (4).

In Ethiopia, where malnutrition and preventable infectious diseases are very common, mental health problems, which are regarded as non life threatening problems, are not given due attention. However, mental health problems account for $12.45 \%$ of the burden of diseases in Ethiopia and $12 \%$ of the Ethiopian people are suffering from some form of mental health problems of which, $2 \%$ are severe cases $(5,6)$.

More recent studies, using samples from diverse populations have suggested that the burden of psychiatric morbidity existing in Africa is very similar to that prevailing in Western countries. Geil and his colleagues reported that $18.5 \%$ of out patients in a teaching hospital in Addis Ababa suffered primarily from psychiatric disorders compared with $9.5 \%$ that are diagnosed as suffering from infectious diseases (7).

Help seeking behavior regarding mental health problems may be affected by different factors such as tolerance and support in the family, lack of money, knowledge and attitude. Only a few studies exist in the world dealing with people's knowledge and attitude towards major mental health problems. A study was, for example, conducted in the Dominica Republic concerning people's attitudes towards mental disorders by involving community leaders and members. All respondents were asked to identify and suggest ideas on the management of individuals with psychoses, alcoholism, and depression depicted in case vignettes. Accordingly a person with a

Department of Epidemiology and biostatistics, Jimma University, P.O. Box 1485, E-mail deribewa@freemail.et, Fax251-7-111450, Jimma, Ethiopia 
vignette of psychoses was diagnosed as suffering from mental illness by $84 \%$ of the community leaders and by $71.2 \%$ of the community members. However, in each of the other vignettes, less than $30 \%$ of respondents thought that mental illness was present (8).

In another study conducted on the perceptions of the public on mental illnesses in USA, a majority of the public identified schizophrenia (88\%) and major depression (69\%) as mental illnesses and that most report maltiaxial explanation combining stressful circumstances with biological and genetic factors. Some of the people associated alcohol $(49 \%)$ or drug abuse (44\%) with mental disorder (9).

One study conducted in Butajira regarding the attitude and practice of people towards mental disorder using key informant questionnaires developed by the WHO showed that, $41 \%$ of the informants preferred modern medicine for neuropsychiatry disorders. None of informants thought that help could be obtained from modern medicine for possession. Epilepsy ranked first followed by schizophrenia in their frequencies of occurrence as perceived by the informants. Schizophrenia was thought to be the most serious mental disorder followed by epilepsy and mental retardation (10).

The study specific objectives include assessing perceived causes and symptoms of mental health problems, determining the attitude of the respondents towards common neuropsychiatric disorders and their effect on access to work opportunities, education and marriage, and their prognosis and severity, assessing the attitude of respondents regarding their preferred place of help for common neuropsychiatric disorders, and assessing the attitude of respondents towards living with people with mental health problems.

\section{Methods}

A cross-sectional survey conducted in Agaro town in December 2003. Agaro town is located $480 \mathrm{~km}$ Addis Ababa and $50 \mathrm{~km}$ from Jimma town. It has eight Kebeles and 7,333 households with a total population of 32,866, where males constitute $48 \%$ of the total (11).

The source population consisted of heads of the households and/or spouses in Agaro town from which the study population was drown.

The assumptions made for the sample size determination were: a proportion of mental distress of $22 \%$ (12), a $95 \%$ confidence interval, a margin of error of $3 \%$. This provided a total sample size of 732 . Since the population is large and the kebeles are scattered, three kebeles were selected by simple random sampling method and the sample size was distributed to each kebele according to probabilities proportional to size. Households were selected using the systematic random sampling method based on their numbers.

A structured questionnaire which was prepared by the investigators and translated into Amharic was used for data collection. The questionnaire was translated again into English to check for consistency with the WHO standard of format. The content of the questionnaire included sociodemographic variables, knowledge on the causes and symptoms of mental health problems, attitude and practice towards four neuropsychiatric disorders (Epilepsy, Schizophrenia, generalized anxiety disorders and major depression) which were presented as vignettes based on the International Classification of Diseases (ICD-10) as shown in the appendix. The vignettes were developed by the investigators based on the proper diagnostic criteria and commented on by experienced colleagues in the Department of Psychiatry of Jimma University. Attitude of respondents about work opportunity, marital prospects, chance of education, severity of the disease and chance of cure by modern medicine of the aforementioned mental health problems were assessed using the mean scores of the five semantic differential scale measurements which are: $1=$ very poor, $2=$ poor, $3=$ fair, $4=$ well, $5=$ very well or $1=$ very serious, $2=$ serious, $3=$ moderate, $4=$ simple, $5=$ very simple. The attitude of the respondents towards living with a person with mental health problem was also assessed using the same five scale measurements. The total mean score of greater than three was taken as a positive attitude for positive statements. The attitude of respondents on the preferred place of help for the Vignette descriptions was also assessed.

Data were collected by the nursing staff of Agaro health center who were trained for two days. Before the data collection, written consent was obtained from the kebele administrators. After explaining the purpose of the study, the respondents were asked to participate voluntarily. Confidentiality was also assured for all the information provided. The collected Data were checked for completeness, cleaned, coded and entered into SPSS-11 for Windows soft ware. Chi-square and F- tests were performed and a P-value of less than 0.05 were taken as statistically significant.

\section{Results}

A total of 728 respondents were interviewed with a response rate of $99.5 \%$. The socio-demographic profiles of the respondents revealed that a large proportion of them were in the age group of 35-44 years $(28 \%)$. A majority of them were Oromo in Ethiopia (38.2\%); Orthodox Christians in religion (50.4\%); Married $(71.7 \%)$ and housewives (37\%). 


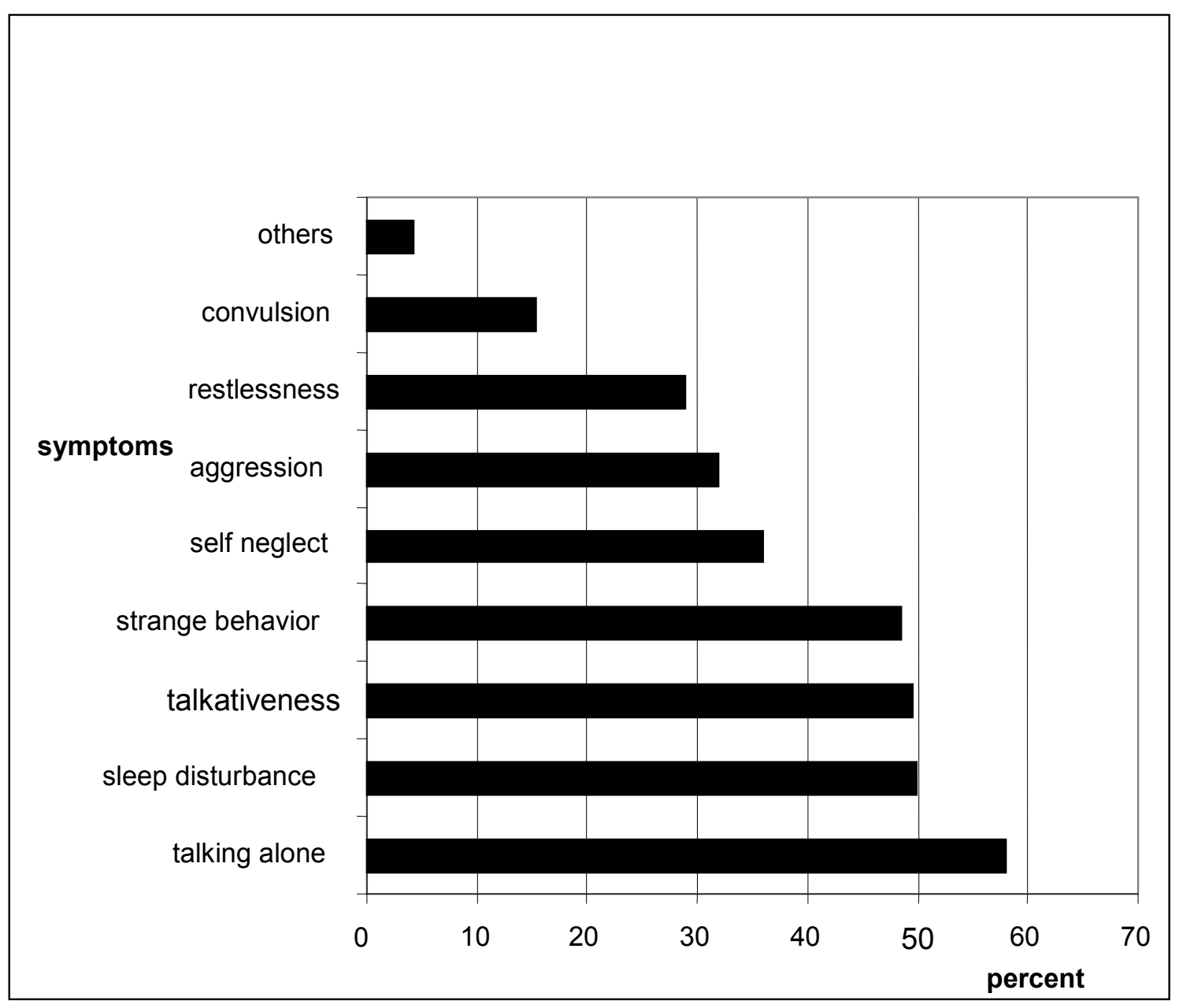

Figure 1: Perceived symptoms of mental health problems, Agaro, Jan. 2004.

Participants' perceived the symptoms of mental health problems as: Talking to oneself, sleep disturbance, talkativeness, strange behavior and aggression as depicted in figure 1 above.

Nearly $4 \%$ of the respondents reported that there was a mentally ill person living in the same household in the last 12 months. Among people reported to have mental health problems, males and khat (a local stimulant) users constituted $61 \%$. The most commonly identified signs of the people with mental health problems were unusual behavior (60\%); talking and laughing alone (46\%); talkativeness (39\%); aggression (28\%), self neglect $(28 \%)$ and restlessness $(28 \%)$.

As shown in figure 2, poverty was the most commonly perceived cause of mental health problems followed by "God's will".
The majority of the respondents $(74 \%)$ identified schizophrenia as a mental health problem while 58, 29 an $15 \%$ of the respondents identified epilepsy, generalized anxiety disorder, and MDD as mental health problems respectively. When asked on the preferred place of help for mental health problems as depicted by vignettes, $76 \%, 83 \%, 72.4 \%$ and $72.5 \%$ of the respondents preferred modern medicine for the treatment of epilepsy, schizophrenia, major depression and generalized anxiety disorders respectively. Holy water was preferred by $(21 \%)$ and $(19 \%)$ of the respondents for the treatment of epilepsy and schizophrenia, respectively. Treatment by family members at home was preferred by $(29 \%)$ and $(21 \%)$ of the respondents for the treatment of MDD and generalized anxiety disorders, respectively (Table 1). 


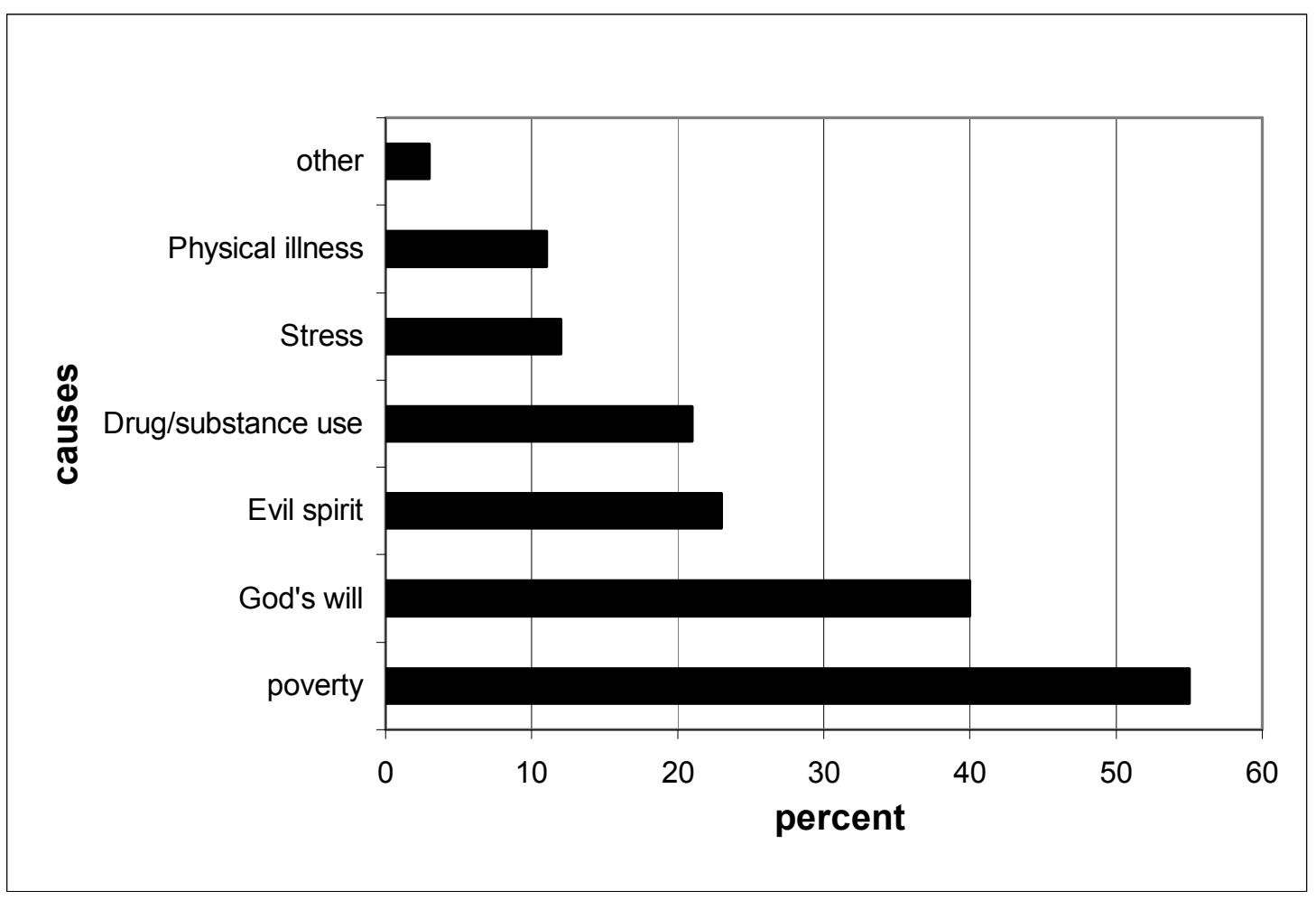

Figure 2: Perceived causes of mental health problems, Agaro, Jan. 2004.

Table 1: Percentage distribution of respondents by their preferred place of help for mental health problems ( $n=728)$, Agaro town, January 2004.

\begin{tabular}{llllllll}
$\begin{array}{l}\text { Mental health } \\
\text { Problem }\end{array}$ & \multicolumn{5}{c}{ Preferred Place of Help } \\
\cline { 2 - 7 } & Family & $\begin{array}{l}\text { Hospital } \\
\text { (Health center) }\end{array}$ & Holy Water & $\begin{array}{l}\text { Traditional } \\
\text { healer }\end{array}$ & $\begin{array}{l}\text { Prayer } \\
\text { houses }\end{array}$ & Witchcraft & Others \\
\hline Epilepsy & 5.6 & 76.0 & 20.6 & 11.7 & 7.6 & 1.5 & 4.4 \\
Schizophrenia & 5.2 & 83.0 & 19.1 & 6.3 & 5.2 & 1.1 & 0.1 \\
MDD $^{+}$ & 29.2 & 72.4 & 10.6 & 3.2 & 6.3 & 0.5 & 0.5 \\
GAD $^{+}$ & 22.5 & 72.5 & 13.6 & 4.4 & 8.1 & 1.8 & 0.4 \\
\hline
\end{tabular}

* = Major depressive disorder

$+=$ Generalized anxiety disorder

There was a statistically significant difference between the more educated and the less educated respondents on their preferred place of help for mental health problems $(p=0.001)$. More educated people preferred modern medicine more often than those who had low educational levels.

The attitude of respondents towards work opportunities, marital prospects, chance for education and cure by modern medicine of the persons with the four mental health problems were positive. Epilepsy was considered as the most serious problem followed by schizophrenia. Major depressive disorder was considered as the least serious problem (Table 2).
Non-literate respondents considered epilepsy as a more serious problem than the other disorders $(\mathrm{F}=5.29, \mathrm{p}=$ 0.001). Respondents with lower educational levels had shown more negative attitudes on the educational opportunity of people with epilepsy $(\mathrm{F}=3.62, \mathrm{P}=0.006)$. The marital prospects and work opportunity of people with schizophrenia were also seen less favorably by illiterate respondents, with respective p-values of 0.024 and 0.009. Females had shown negative attitudes on the marital prospects of major depressive disorders more often than the males $(\mathrm{F}=6.71, \mathrm{P}=0.01)$.

The respondents were also asked on their attitudes towards living with people who had mental health 
Table 2: Mean scores of attitude for work opportunity, marital prospects, chance of education, severity and chance of cure by modern medicine of mental health problem ( $n=728)$, Agaro town, January 2004.

\begin{tabular}{llllll}
$\begin{array}{l}\text { Mental health } \\
\text { Problems }\end{array}$ & \multicolumn{2}{l}{ Mean Scores } & & & \\
\cline { 2 - 6 } & Work opportunity & Marital prospects & Severity & Chance of cure & $\begin{array}{l}\text { Chance of } \\
\text { education }\end{array}$ \\
\hline Epilepsy & 3.68 & 3.68 & 2.01 & 3.38 & 3.74 \\
Schizophrenia & 3.88 & 3.76 & 2.70 & 3.84 & 3.82 \\
MDD $^{+}$ & 4.51 & 4.45 & 3.70 & 4.21 & 4.43 \\
GAD $^{+}$ & 4.10 & 4.04 & 3.30 & 3.90 & 4.04 \\
\hline
\end{tabular}

* = Major depressive disorder

$+=$ Generalized anxiety disorder

problem as depicted in the vignettes in the same house and also as a neighbor. Over $90 \%$ of the respondents had positive attitudes towards living with people major depression in one house or as neighbors. Twenty-four and thirty-five percent of the respondents had negative attitude towards living with the persons with epilepsy and schizophrenia in the same house, respectively (Table 3).
Illiterate respondents had negative attitude more than the literates to live in the same household with the cases of schizophrenia $\left(\mathrm{X}^{2}=50.59, \mathrm{P}=0.001\right)$ and epilepsy $\left(\mathrm{X}^{2}=\right.$ $48.59, \mathrm{P}=0.001)$. Epilepsy and schizophrenia were considered contagious diseases by $11 \%$ and $0.8 \%$ of the respondents in that order.

Table 3: Percentage distribution of the respondents by their attitude towards living with a person with mental health problem ( $\mathrm{n}=\mathbf{7 2 8})$, Agaro town, January 2004.

\begin{tabular}{lllllll}
\hline \multirow{2}{*}{ Mental health problem } & \multicolumn{3}{l}{$\begin{array}{l}\text { Attitude towards living in the } \\
\text { same house }\end{array}$} & \multicolumn{3}{l}{ Attitude towards living as neighbor } \\
\cline { 2 - 7 } & Positive & Neutral & Negative & Positive & Neutral & Negative \\
\hline Epilepsy & 71.2 & 4.9 & 23.9 & 79.8 & 4.5 & 15.7 \\
Schizophrenia & 58.0 & 6.6 & 35.4 & 72.7 & 5.1 & 22.3 \\
Major depressive disorder (MDD) & 92.0 & 2.9 & 5.1 & 93.3 & 1.9 & 4.8 \\
Generalized anxiety disorder & 83.8 & 4.4 & 11.8 & 88.3 & 4.3 & 7.4 \\
\hline
\end{tabular}

\section{Discussion}

The respondents recognized only overt psychotic symptoms such as talking to oneself excessive talkativeness and aggression as signs of mental health problem. The possible explanation for this is a lack of health information on the symptoms of mental health problems. This finding is in agreement with that of the Butajira study (10). This may indicate that people with less severe manifestation of mental health problems will not be recognized unless they show the overt psychotic symptoms. This could be the main reason why only $4 \%$ of the respondents reported the presence of a mentally ill person in their households in the last 12 months. If the respondents had recognized less severe forms of mental health problems, the above figure might have been higher.

In this study, a significant number of people implicated supernatural powers as causing mental health problems which is in agreement with other studies conducted in Ethiopia $(13,14)$. Such traditional notions whereby supernatural powers are attributed to controlling the well being of an individual's mind are widespread in all ethnic or religious groups in Ethiopia (15). Similar results were also observed in other African studies $(16,17)$. However, poverty, stress and physical illness were also mentioned as causes of mental health problems, which are in agreement with western studies $(9,18)$.
A person depicted by psychosis vignette was diagnosed as suffering from mental health problem by $74 \%$ of the respondents which is in line with a study conducted in the Dominica Republic (8). However, major depressive disorder and generalized anxiety disorders were recognized by $15 \%$ and $29 \%$ of respondents respectively as mental health problems. This could be due to their less severe manifestations. Modern medicine was preferred by the majority of respondents for the treatment of neuropsychiatric disorders unlike the Butajira study (10). This could be due to the effect of Team Training Program (TTP) of Jimma University and Agaro Health Center. The other explanation could be the effect of the methodological differences. In the Butajira study key informants were asked on their preferred place of help for psychiatric symptoms unlike the current study. In our study it is noted that more educated people preferred modern medicine than their counter parts. Holy water was preferred more by Christians than Muslims like that of the Butajira study (10). A significant number of people preferred home treatment for major depression and generalized anxiety disorders. This could be due to the perception of the people as they consider these disorders as less serious.

The attitudes of the people towards access work opportunity, marital prospects, chance of education and 
cure by modern medicine were favorable for the four mental health problems (epilepsy, schizophrenia, MDD and generalized anxiety disorders) contrary to other studies $(10,14)$. This could be due to the impact of the long term teaching, at the health center of Agaro town that gives services for chronic illnesses like epilepsy. However, the less educated respondents still had negative attitude on marital prospects and work opportunity for schizophrenics and educational opportunity of epileptics.

One out of four and one out of three people respectively had negative attitudes towards living with people with epilepsy and schizophrenia. Less educated people had more negative attitudes towards living with people with mental problems. This could be due to lack of information on the nature and causes of the diseases.

Eleven percent of interviewees believed that epilepsy is contagious disease. When compared with that of the Tekle-Haimanot et al study (14), it is less significant and this may be due to the effect of the health agencies described above.

The people in their study area recognized only overt psychotic symptoms and a majority of them did not recognize major depression and generalized anxiety disorders as mental health problems. A significant number of people implicated supernatural power as causes of mental health problems. Illiterates had negative attitudes towards living with people with of schizophrenia and epilepsy in the same household as well as on the abilities of those people to work more often than the literates. We recommend that Information education communication (IEC) programs should be launched to teach the community on the causes, symptoms, treatability of mental health problems and the roles of people with mental health problems in the society.

\section{Acknowledgment}

The study was funded by the Research and Publication Office of Jimma University.

\section{Reference}

1. WHO. Mental health; New understanding new hope. The World Health Report .WHO, Geneva, Switzerland, 2001.

2. World Bank. World Development Report. Inventory on Health. New York; Oxford university press, Oxford, UK.1999.

3. Desjarlias R, Eisenburg L, Good B, Kleinman A. World mental health: Problem and properties in low income countries. Oxford University press INC, Oxford, UK. 1995.

4. WHO. Mental health care in developing countries; a critical appraisal in research findings. Technical report series, 698, WHO, Geneva, Switzerland. 1994.
5. Abdulahi H, Hailemariam D, Kebede D. Burden of disease in Butajira, southern Ethiopia. EMJ, 2001;39(4):271-281.

6. Mesfin A, Aboud F. Mental illness in Ethiopia: In Kloos $\mathrm{H}$ and Zein AZ (eds). The ecology of health and diseases in Ethiopia, 1993;493-506.

7. Geil R. Patterns of morbidity in a general out patient population as a guide to priorities in medical curriculum. Trop Geogr Med, 1968;20:281-7.

8. Kuhn R. Attitude towards mental illness in Common Wealth of Dominica. Rev Panam salud public, 2000;7(3): 148-54.

9. Link S. Public perception on mental illness, Level, causes, dangerousness and social distance. AMJ public health, 1999;89(9): 7328-33.

10. Alem A, Jacobsson, Araya M, Kebede D, Kullgren G. How are mental disorders seen and where is help sought in rural Ethiopian community? Acta Psychiatrica Scand, 1999;100:40-47.

11. Central Statistical Authority. The 1994 Population and Housing Census of Ethiopia, results of the Orommya Region, Addis Ababa, Ethiopia, April 1996.

12. Mekonen E, Esayas S. Correlates of mental distress in Jimma town, Ethiopia. Ethiopian Journal of Health Sciences, 2003;1:39-49.

13. Shibre T, Negash A, Kullgren G et al. Perception of stigma among family members of individuals with schizophrenia and major depressive disordersin rural Ethiopia. Social Psychiatry and Psychiatric Epidemiology, 2001;36(6):299-303.

14. Samuel M. Perception of mental and physical illnesses in north-western Ethiopia, causes, treatment and attitude. Journal of Health Psychology, 1999;4(4):531-549.

15. Alem A, Desta M, Araya M. Mental health in Ethiopia. EPHA Expert Group Report. Ethiop J Health Dev, 1995;9(1):57-62.

16. Coleman R, Lopptl, Walraven G. The treatment gap and primary health care for people with epilepsy in rural Gambia. Bulletin of World Health Organization, 2002;80:378-383.

17. Tekle-Haimanot R, Forsgren L, Gebremariam A etal. Attitude of rural people in central Ethiopia towards epilepsy. Soc Sci Med, 1991; 32(2): 203-209.

18. Emmanuel S, Jean C, Carol J. Schizophrenia: People's perception in Quebec. CMAJ, 2001;164(9): 1299-1300.

\section{Appendix-I}

\section{Case Vignettes}

1. Mr. (W) has occasional falling accident followed by rigidity of limbs and jerky moment of the whole body. He has drooling of saliva and rolling of the eye upward during the attack. After the attack he attack he goes to sleep for 10 minutes followed by headache. 
2. Mr. (X) a 25 years old single teacher, became suspicious of his friends that they are plotting against him since 8 months. He gradually avoided interacting with others and started talking alone. He laughs alone for no reason. He has difficulty in falling asleep. He sometimes avoids eating, as he believed that the food is poisoned.

3. Ms. (Y) is 28 years old unmarried secretary who lives alone. She has been feeling sad for the past one month. She was tearful and felt hopeless and worthless. She has been unable to sleep well and slow in her activities because of which she couldn't go to work for the last two weeks. She attempted to commit suicide 5 days back. It was reported that hear elder brother had similar illness.

4. Mr. (Z) experiences anxiety, fear, and anticipation of misfortune for the last 6 months. He worries about his financial problems. He has headache, backache, and abdominal pain at different times. He can't enjoy himself and sometimes he is restless. 

